\title{
DIGRESSÕES ACERCA DA NOÇÃO DE ESTILO: CONTRIBUIÇÕES PARA UMA PERSPECTIVA NÃO MODERNA DO EU
}

\author{
DIGRESIONES ACERCA DE LA NOCIÓN DE ESTILO: \\ CONTRIBUCIONES PARA UNA PERSPECTIVA NO MODERNA DEL YO \\ DIGRESSIONS ABOUT STYLE NOTION: CONTRIBUTIONS TO A NON- \\ MODERN PERSPECTIVE OF THE SELF
}
Ronald Arendt ${ }^{1}$, Laura Cristina de Toledo Quadros ${ }^{1}$ e Márcia Oliveira Moraes²

${ }^{1}$ Universidade do Estado do Rio de Janeiro, Rio de Janeiro/RJ, Brasil

${ }^{2}$ Universidade Federal Fluminense, Niterói/RJ, Brasil

\begin{abstract}
RESUMO: O presente artigo pretende discutir a noção de estilo como possibilidade de rever a noção de sujeito numa perspectiva não moderna. A inspiração que nos dá suporte advém da Teoria Ator-rede (TAR), proposta por Bruno Latour e outros autores. O ponto de partida da TAR são as conexões, os laços que articulam humanos a não humanos, tecendo e compondo o mundo em que vivemos. A questão central diz respeito a pensarmos o eu como uma construção relacional e, nesse sentido, recorremos a noção de estilo para desenvolver essa reflexão. Três filósofos contemporâneos - Alfred North Whitehead, Etienne Souriau e Gilles Deleuze - são referências necessárias na compreensão da TAR e nos auxiliam na discussão do conceito de estilo. Discorremos sobre como cada um desses autores aborda esse tema e concluímos indicando os desdobramentos de tais contribuições para pensarmos o eu para além de uma interioridade.

PALAVRAS-CHAVE: Teoria Ator-Rede; Psicologia; Estilo; Eu.
\end{abstract}

RESUMEN: En el presente artículo se discute la noción de estilo como una posibilidad de revisar la noción de sujeto a partir de una perspectiva no moderna. La inspiración en que se apoya esa idea proviene de la teoría del actor-red (TAR), propuesta por Bruno Latour y otros autores. El punto de partida de la TAR son las conexiones, los lazos que articulan humanos a no humanos, tejiendo y componiendo el mundo en que vivimos. La cuestión central se refiere a pensar en el yo como una construcción relacional y, en ese sentido, recurrimos a la noción de estilo para desarrollar esa reflexión. Trés filósofos contemporáneos - Alfred North Whitehead, Etienne Souriau y Gilles Deleuze - son las referencias necesarias en la comprensión de la TAR y ayudarán con el concepto de estilo. Se discute cómo cada uno de esos autores aborda esa cuestión y se llega a la conclusión sugiriendo el desarrollo de dichas contribuciones para pensar el yo más allá de una interioridad.

PALABRAS CLAVE: Teoría Del Actor-Red; Psicología; Estilo; Yo.

ABSTRACT: The present article intends to discuss the notion of style as a possibility to revise the notion of subject in a non-modern perspective. The inspiration that supported us came from the Actor-Network Theory (ANT), proposed by Bruno Latour and other authors. ANT's starting points are the connections, the ties that articulate humans and non-humans, weaving and composing the world in which we live. The central issue in this work was to think about the self as a relational construction and to resort to the notion of style in order to develop this reflection. Three contemporary philosophers - Alfred North Whitehead, Etienne Souriau and Gilles Deleuze were essential references in the understanding of ANT and assisted us in discussing the concept of style. In the article we discuss how each of these authors addresses this theme and conclude by indicating the unfolding of such contributions in order to reflect on the self beyond interiority.

KEYWORDS: Actor-Network Theory; Psychology; Style, Self. 
Repetir, Repetir - até ficar diferente. Repetir é um dom do estilo.

(Manoel de Barros)

\section{De onde partimos}

Historicamente, uma das preocupações da Psicologia enquanto ciência foi a de buscar explicações para os mecanismos que determinam o funcionamento mental ou, num sentido mais amplo, o funcionamento humano. Da noção de consciência à noção de personalidade, subjaz implícito o que acontece "por dentro" desse humano, tanto no sentido daquilo que o determina quanto do que o diferencia (Figueiredo \& Santi, 2008). Da noção de indivíduo à noção de sujeito, buscou-se delimitações que nos separassem uns dos outros e, em alguns aportes teóricos, que nos separassem do mundo, destacando-se uma interioridade solitária e inevitável. A ideia de um "eu” purificado permeia muitas tendências de pensamento na Psicologia e, segundo Rose (2001), isso promoveu nesta área o desenvolvimento de técnicas de conduta de si que geraram imperativos e imposições de modelos tanto de autoconhecimento quanto de controle. Segundo este autor,

As disciplinas "psi”, em parte como consequência de sua heterogeneidade e falta de um paradigma único, adquiriram uma peculiar capacidade penetrativa em relação às práticas para a conduta da conduta. Elas têm sido não apenas capazes de fornecer toda uma variedade de modelos do eu, mas também de fornecer receitas praticáveis para a ação em relação ao governo das pessoas, exercido por diferentes profissionais, em diferentes locais. Sua potência tem sido aumentada ainda mais por sua capacidade para suplementar essas qualidades praticáveis com uma legitimidade que deriva de suas pretensões a dizer a verdade sobre os seres humanos. Elas se disseminaram rapidamente, por meio de sua pronta traduzibilidade, por programas para remoldar os mecanismos de auto direção dos indivíduos, estejam esses na clínica, na sala de aula, no consultório, na coluna de conselhos das revistas ou nos programas confessionais da televisão. (Rose, 2001, p. 46)

Assim, em diferentes perspectivas teóricas na Psicologia, há investimento em construir conceitos que fundamentem a noção de "eu” em suas diversas versões. Nossa proposta nesse texto não é fazer um resgate ou mapa histórico desses conceitos e muito menos formular uma nova conceituação. Ao que nos propomos então? Direta e brevemente: propomo-nos a explorar as possibilidades de tratarmos da noção de sujeito longe do referencial moderno (Latour, 1994), lançando mão da teoria ator-rede e da noção de estilo. Antes, no entanto, de melhor e mais detidamente apresentarmos nosso propósito, consideramos pertinente situar brevemente o leitor a respeito do que orienta nossas reflexões.

A inspiração que nos dá suporte advém da Teoria ator-rede (TAR), proposta por Bruno Latour (1994, 2007, 2008, 2012) e outros autores ${ }^{1}$, que apresenta uma ontologia de geometria variável, afirmando a anterioridade das conexões por relação aos termos. Por essa via, a TAR coloca em xeque nossa modernidade, articulada em torno de dicotomias que separam sujeito de objeto, natureza de sociedade. Ao trazer a provocação de que jamais fomos modernos, Latour (1994) nos convida a repensar tais dicotomias, apontando 
não para as separações que definem os polos dessas dicotomias, mas para o solo híbrido no qual se engendram. O ponto de partida da TAR são as conexões, os laços que articulam humanos a não humanos, tecendo e compondo o mundo em que vivemos.

Sob esta ótica, os acontecimentos são movimentos nos quais objetos e pessoas estão em conexão, formando híbridos indissociáveis. Portanto, a ênfase está nas conexões, articulações, alianças, constituindo redes que produzem formas, relações, deslocamentos impermanentes. A ideia de rede aqui exposta não se atém a uma simples associação, ressaltando-se o caráter ativo e transformador dos fenômenos em rede, visto que o interesse está não somente nos vínculos estabelecidos, mas no que eles produzem, no que "faz fazer" (Latour, 2008).

Latour (1994) aponta também que estamos envolvidos num mundo de objetos híbridos. Sofremos inúmeras interferências que afastam a ideia de um sistema puro, livre de afetações. Segundo Moraes (2003):

A noção de rede não é, para Latour, oposta à dicotomia moderna. Mas é aquilo que nos faz passar ao largo destas dicotomias. A noção de rede encontra ressonâncias filosóficas com o trabalho de Serres e de Deleuze e Guattari. É o próprio Latour que indica que a noção de rizoma é uma palavra perfeita para rede. Uma rede é um mapa, e não um decalque, quer dizer, que a rede de atores é aberta, heterogênea de modo que a princípio é possível estabelecer todo e qualquer tipo de conexão, sem que seja uma necessidade de direito a redundância de elementos-chaves. $\mathrm{Na}$ linguagem de Latour podemos dizer que rede é sinônimo de híbridos, de quase objetos. Enquanto a lógica da modernidade é a lógica do decalque, a lógica da rede é aquela do mapa. (pp. 1-2)

Outra questão a ser esclarecida refere-se ao termo ator. "Segundo a teoria ator-rede, um ator é tudo e todos que agem num sistema incluindo humanos e não-humanos, ou seja, é tudo o que possa gerar algum impacto na rede” (Quadros, 2015, p. 1186). Assim, a ação é um processo distribuído entre os atores que estão conectados, podendo sofrer sempre novas conexões e afetações. "Isso significa dizer que um ator não se define pelo que ele faz, mas pelos efeitos do que ele faz. E mais, o ator não se confunde com o indivíduo, ele é heterogêneo, díspar, híbrido” (Tsallis, Ferreira, Moraes, \& Arendt, 2006, p. 65). Portanto, essa perspectiva traz outras luzes para pensarmos a ideia não mais de um sujeito em si, e/ou de um objeto "lá fora", mas sim compreendê-los como um processo de afetações mútuas, um movimento dos eventos da rede na qual eles se encontram. Mas eles também são "atores", ou seja, interferem, são ativos nessa rede, produzem efeitos. Os efeitos aqui não são, de forma alguma, fruto de uma linearidade; ao contrário, refletem as múltiplas possibilidades de agenciamentos.

Nesse sentido, a proposta de "re-ver" a noção de eu produz um deslocamento de uma Psicologia, centrada no indivíduo e na individualização, para a possibilidade de abrangermos um sujeito em rede, produzindo e sendo produzido pelos agenciamentos compostos na relação humanos /não humanos, incluindo-se aí objetos, eventos, não-humanos. Isso envolve s noção de fluxo, conexão, mediação, trazendo um caráter dinâmico e fluído, que flexibiliza os contornos de um eu, tornando-os híbridos e permeáveis. Essa é uma temática desafiante para a Psicologia, pois em sua constituição como ciência, apoiada na proposição cartesiana de um existir humano circunscrito à racionalidade e definido por ela, vem buscando explicar o que caracteriza o eu. Latour, um dos autores que nos inspira, afasta-se 
desse viés essencialista e interessa-se pelo que "faz-fazer" (Latour, 2008), ou seja, enfatiza as ações produzidas na rede, as heterogeneidades que as compõem e as associações que o referido autor compreende como sendo locais e provisórias. Ao transpormos essa leitura para a noção de eu, destacamos, inicialmente, o caminho de tratá-la como uma construção relacional, processual e aberta. Com isso, coloca-se em xeque tanto a hierarquização nas relações sociais quanto as certezas e estabilidades que sustentam as generalizações e formulações de verdade no que concerne ao sujeito no mundo. Recorremos mais uma vez a Rose (2001), que reafirma o desafio de buscar outras formas de compreensão para pensarmos esse eu:

As estratégias políticas motivadas pelos ideais da identidade estão, sem dúvida, imbuídas, com igual frequência, tanto pelos valores nobres do humanismo e de seu compromisso com a liberdade individual quanto por uma vontade de dominar ou purificar em nome da identidade. Mas quando nosso próprio século termina, talvez seja hora de tentar contabilizar os custos e não apenas os lucros de nossos projetos de identidade. E um pequeno mas importante elemento dessa contabilidade de custos está na identificação das contribuições feitas a esse regime de subjetivação pela psicologia, como o discurso que por cerca de 150 anos tem nos falado - algumas vezes por meio de comandos brutais, outras vezes por meio de impassíveis pesquisas, outras vezes ainda por meio de murmúrios sedutores e confortantes - das verdades sobre nós mesmos. (Rose, 2001, p. 52)

Portanto, seguindo os rastros acima apontados, nossa proposta no decorrer do texto é a de discutir os contornos dessa ideia de sujeito, articulada às formulações da TAR, através de um olhar não moderno (Latour, 1994). Consideramos essa temática pertinente e atual tanto pelo que nos alertou Rose (2001) quanto pela necessidade de inserirmos referenciais na psicologia que possam contribuir para pensarmos esse sujeito já interferido pela relação com não-humanos, como nos sugerem os estudos CTS. Partiremos, então, da questão norteadora: é possível pensar uma noção de eu não-moderna? Não há aqui, como já dissemos, nem a pretensão de uma resposta que esgote a complexidade do tema, e menos ainda a formulação de um modelo não-moderno, o que se constituiria numa contradição com a própria orientação que fundamenta nossa reflexão. O que pretendemos é criar algumas proposições que nos permitam escapar das modelações e, ao mesmo tempo, compor um diálogo com autores que tangenciem essa questão norteadora aqui delineada.

Para seguirmos a trilha escolhida, nos apoiaremos na noção de estilo, considerando as singularidades tecidas nessa formação em rede. Nosso interesse é inserir tal noção primeiramente numa abordagem "não" moderna para, posteriormente, avaliar sua riqueza e sua potência como conceito na Psicologia ${ }^{2}$. Usamos o termo digressão para ilustrar os desvios momentâneos que faremos na busca por incluir o leitor em nossa construção de pensamento, a fim de debater a temática em questão. Assim, nosso objetivo é trazer outros contornos para noção de eu a partir da noção de estilo, num encontro entre a Psicologia e a TAR. Consideramos que tal discussão traz desdobramentos interessantes para que nossas práticas se desloquem de uma dimensão individualizante para alcançar possibilidades múltiplas e abrangentes. 
Convidamos, pois, o leitor a nos acompanhar em nossas reflexões que buscam desenhar através da noção de estilo uma singularidade que dialogue com a proposta da TAR.

\section{Sobre a noção de "estilo": uma possibilidade em rede}

Frequentemente, lemos e ouvimos considerações sobre o estilo. A quem interessaria ler sobre estilo? Os psicólogos teriam interesse na noção de estilo? Acreditamos que sim, considerando principalmente as perspectivas não modernas de práticas psi (Arendt, 2008). Por isso, nos propusemos a escrever este ensaio. Entendemos ser relevante refletirmos sobre sua conceituação e avaliarmos sua contribuição para, por um lado, melhor pensar alguns aspectos na filosofia e na arte e, por outro, alguns aspectos da Psicologia contemporânea.

O que seria então o estilo? Três filósofos contemporâneos, Alfred North Whitehead (1959), Etienne Souriau (2009) e Gilles Deleuze (Deleuze \& Parnet, 2008), todos três referências necessárias na compreensão da TAR, podem nos guiar na compreensão do conceito. Discorreremos a seguir sobre como cada um desses autores aborda esse tema. Alertamos ao leitor, mais uma vez, que durante esse passeio pelos referidos autores, alguns desvios momentâneos ocorrerão. Eles são importantes para sustentar nossa proposição. Segue, portanto o convite para que nos acompanhe também nas breves digressões.

\section{O estilo a partir de Whitehead, Souriau e Deleuze: digressões}

Neste momento do texto, traremos três interlocutores que perpassam também pelos escritos de Latour (2008, 2012), para pensar a noção de estilo, um dos pontos fundamentais para a proposta desse artigo.

Comecemos por Whitehead (1959). Ao final de uma conferência intitulada "Os fins da educação", dirigida à Associação Matemática da Inglaterra, em 1916, na qual discute a forma pela qual se efetua o ensino da matemática nas escolas inglesas, o filósofo ressalta aquela que seria "a mais austera de todas as qualidades mentais", o estilo. A qualidade estética do estilo na arte, na literatura, na ciência, na lógica, em qualquer execução prática, seria a obtenção de um fim através de uma "mente educada", caracterizada por uma "contenção" que envolve uma moralidade: o senso do estilo estaria no administrador que odiaria o desperdício, no engenheiro que economizaria material, no artesão que preferiria um bom trabalho. Com o estilo, a mente não é "distraída com irrelevâncias" e tem mais probabilidade de atingir seus fins. O estilo seria a exclusividade do especialista. "Quem já ouviu falar do estilo de um pintor amador? Pergunta ele: estilo será sempre o produto do estudo de um especialista, sua "contribuição peculiar" à cultura” (Whitehead, 1959, p. 25).

Já Souriau (2009) não utiliza o termo diretamente, mas as teses que desenvolve permitem caracterizá-lo indiretamente com bastante clareza. Souriau é o filósofo da "obra a fazer". Para ele, o artista não é propriamente o autor de uma obra, ele a instaura, ele trilha um trajeto buscando levá-la até o fim. Neste trajeto em que nada é dado de avanço, a execução da obra é permeada por perigos: uma pincelada em falso pode inviabilizar o quadro, uma martelada inviabilizar a escultura. Assim, não há garantias que ele chegue ao 
fim deste trajeto com a obra realizada, o risco do erro coexiste com sua execução. Neste sentido, ele será responsável por levá-la a cabo. Souriau (2009) formula então uma frase que sintetiza seu argumento: "O que fez grandes Miguelangelo ou Beethoven, o que os fez geniais, não é seu próprio gênio, é sua atenção à genialidade, não neles mesmos, mas à obra" (p. 161).

Antes de prosseguirmos com Deleuze, caberia colocar algumas questões que envolvem um posicionamento teórico. É interessante observar que tanto Whitehead quanto Souriau, para sustentar suas argumentações, fazem uso de uma dualidade: para o primeiro, o estilo advém da relação do administrador com o material a não ser desperdiçado, do engenheiro com material a ser economizado, do artesão com o seu trabalho. Para o segundo, da relação de Miguelangelo ou Beethoven com suas obras. Em nossas reuniões de equipe no grupo Entre_redes ${ }^{3}$, ainda que nossa proposta de estudo e pesquisa fosse operar no ambiente conceitual da não modernidade (no contex to da teoria do ator-rede), imperceptivelmente nos víamos utilizando uma argumentação moderna. Trabalhando com os autores em pauta, por vezes caíamos na armadilha de interpretar a dualidade que identificávamos em seus argumentos a partir da dicotomia moderna que separa sujeito X objeto. O "sujeito" seria o engenheiro ou o economista, e o "objeto" seus materiais. Ou os "sujeitos" seriam Miguelangelo ou Beethoven e o "objeto" suas obras. O fato é que estávamos raciocinando de forma moderna ao perguntarmos se Schubert compunha lieder belíssimos ou se os lieder de Schubert é que eram belíssimos; se era mãe italiana que cozinhava de forma deliciosa ou a sua macarronada é que era deliciosa. Se Christian Dior teria sido um costureiro extraordinário ou é o design de moda de Dior que seria extraordinário. No decorrer deste artigo, vamos argumentar que é possível pensar o estilo sem cair na dualidade moderna na qual ou é o sujeito quem faz ou é a obra que faz.

Caberia descrever sucintamente a posição não moderna da relação sujeito/objeto recorrendo a Latour (2007), quando relata sua visita a uma exposição do Museu de História Natural de Nova York. Havia ali, sendo expostas, duas séries, duas versões do conhecimento sobre fósseis: a progressiva transformação de fósseis de cavalos e a progressiva transformação das suas interpretações. Numa série, os fósseis, noutra série, as interpretações dos cientistas sobre estas transformações. Reportando-se ao psicólogo e filósofo americano William James, Latour observa que este, com seu bom humor, criticava o "salto mortal" que iria do objeto (os cavalos) ao sujeito (as interpretações). Em outras palavras, não se "pula" de uma sequência de argumentos a outra. Trata-se de movimentos diferentes. Por um lado, os pesquisadores chegarão a um resultado (sempre provisório) sobre sua interpretação no que tange ao modo de existir dos cavalos, por outro, como num quebra-cabeças, os pesquisadores farão o encadeamento dos fósseis chegando ao cavalo tal como é conhecido hoje. Diz Latour (2007):

A descoberta crucial de James é que estes dois personagens - objeto e sujeito não são os pontos adequados de partida para qualquer discussão sobre aquisição de conhecimento; eles não são a âncora à qual ligar a ponte vertiginosa lançada sobre o abismo de palavras e o mundo. Antes, eles são gerados como subprodutos. (p. 9)

Em outros termos, objeto e sujeito são pontos de chegada, eles são constituídos nos trajetos através dos quais o conhecimento é retificado. Anos depois, em uma de suas obras mais recentes, intitulada Investigação sobre os modos de existência, num capítulo intitulado 
"Uma perigosa mudança de correspondência", Latour (2012) retoma o tema. Agora não são mais fósseis e interpretações sobre fósseis, mas mapas sobre trilhas em montanhas e a montanha. Após analisar as cadeias extremamente intrincadas que levam à elaboração destes mapas, sua extrema utilidade para o montanhista que pretende escalar um morro cheio de aclives e precipícios, ele insiste no paralelismo da primeira série com a segunda série - montanha que se reproduz e continua em seu local sem muito se importar com os humanos que desejam explorá-la elaborando roteiros na forma de mapas. Mais uma vez Latour (2012) dirá que:

é um dos efeitos da referência engendrar ao mesmo tempo um tipo de objeto conhecido e um tipo de sujeito conhecedor em cada uma de suas extremidades; objeto e sujeito que não são mais as causas mas apenas as consequências de tais cadeias e de certa forma seus produtos. (p. 102)

Com essas argumentações, Latour $(2007,2012)$ nos leva a problematizar as dualidades modernas, colocando-as em xeque e nos ofertando ferramentas para conceituarmos o estilo longe de tais dualidades.

Neste ponto, entendemos que algumas observações devem ser feitas para situar este último livro de Latour (2012) que, segundo ele, sintetiza vinte e cinco anos de suas investigações. Ocorre uma mudança de postura frente aos modernos. Ao invés de, como sempre em seus textos anteriores, desconfiar deles ${ }^{4}$ (eles dizem uma coisa e fazem outra) o autor decide investigar o que eles "efetivamente" fazem. Quais seriam os seus modos de existência? Um personagem, uma antropóloga, terá como tarefa investigar como os modernos lidam com a ciência, o direito, a religião, a política, a técnica, a ficção, a economia. Não nos interessam aqui tanto os modos, mas o método que a antropóloga utilizará para rastreá-los. Este será importante para elaborar nossa análise sobre o estilo. Latour (2012) insistirá que cada modo tem uma chave de interpretação, uma forma específica de argumentação. Ocorreria um erro de categoria se a argumentação em um modo fosse sustentada em outro modo (por exemplo, se utilizarmos um argumento científico numa questão religiosa ou um argumento religioso numa questão de direito). Nestes termos, segundo Latour, cada modo teria o que o autor chama de um conjunto de condições de felicidade a serem preenchidas (ou infelicidade, quando não preenchidas), uma trajetória fundada nos instrumentos, equipamentos, especialidades, julgamentos, valores específicos de cada modo. Para nomear o que distingue um tipo de "condição de felicidade" de outro e para designar estas trajetórias, Latour (2012) se reportará mais uma vez a William James e ao tratamento que este dá à expressão preposição, "enquanto uma tomada de posição que vem antes de uma proposição e que decide a maneira pela qual se deve tomá-la e que constitui sua chave de interpretação" (p. 69). Portanto, essa seria uma "pré-posição", um movimento sutil que aponta o deslocamento daquilo que se anunciará. Mas, se tomarmos as preposições em sua função gramatical ${ }^{5}$, vemos que ela estabelece conexões, relações de afetação mútua que produzem sentidos. Então, as preposições "a”, “ante”, “com”, “depois”, "entre”, etc, "engajam de forma decisiva na compreensão do que se seguirá oferecendo o tipo de relação necessária à tomada de experiência do mundo" (Latour, 2012, p. 244). Elas indicam um sentido e estabelecem uma tonalidade. "Cada preposição define portanto uma maneira de fazer sentido que diferirá dos outros” (Latour, 2012, p. 244). Ele dá um exemplo: se você entra numa livraria e segue a direção da estante com a indicação "romances", isto estabelece uma tonalidade de leitura e engaja o leitor de maneira totalmente diferente daquela 
que ocorreria se você seguisse a indicação “documentário”. É importante ressaltar que na língua portuguesa, além das preposições essenciais, dispomos também das conjunções, das preposições acidentais, das palavras de outra classe gramatical que assumem essa função de conectar termos colocando-os nessa relação de vinculação. É isso que aqui nos interessa e o que irá nos nortear daqui por diante nos comentários e exemplos que explicitaremos, a preposição como o que conecta e confere sentidos.

Chegados a este ponto de nosso texto, lançamos uma questão: não poderíamos utilizar esta forma de operar com a preposição para pensar o estilo em cada modo? Na seção final, ao trazermos estas questões para a psicologia, aprofundaremos esta argumentação. Por ora, retornemos à Deleuze

"Eu gostaria de dizer o que é um estilo" diz Deleuze, logo no início do seu livro Dialogues com Claire Parnet (2008). "Um estilo é conseguir gaguejar em sua própria língua... Não ser gago na palavra, mas ser gago na língua. Ser como um estrangeiro em sua própria língua. Fazer uma linha de fuga" (Deleuze \& Parnet, 2008, p. 10). Em O que é filosofia, escrito com Felix Guattari (Deleuze \& Guattari, 1995), o tema é retomado. No sétimo capítulo intitulado "Percepto, Afeto e Conceito" os autores expõem uma concepção particularmente original da arte: a arte conserva a pose da jovem há cinco mil anos, conserva o ar de agitação, a respiração e a luz que havia tal dia do ano anterior e que não depende mais daquele que respirava naquela manhã, conserva um sorriso sobre a tela feito de cores, de traços, de sombra e luz. "O que se conserva da arte é um bloco de sensações, isto é, um composto de perceptos e de afetos" (Deleuze \& Guattari, 1995, p. 154) que independe de seu modelo e do seu criador. O que faz o artista? "Ele faz com que este composto se mantenha em pé por si só” (Deleuze \& Guattari, 1995, p. 155).

A cada vez o estilo é preciso - a sintaxe de um escritor, os modos e ritmos de um músico, os traços e cores de um pintor - para se elevar das percepções vividas ao percepto, das afecções vividas ao afeto. (Deleuze \& Guattari, 1995, p. 160)

O estilo será então o método que variará de artista a artista na elaboração do bloco de sensações. O escritor

se serve de palavras, mas criando uma sintaxe que as faz passar à sensação e faz gaguejar a língua corrente, ou tremer, ou gritar, ou mesmo cantar: é o estilo, o "tom”, a linguagem das sensações ou a língua estrangeira na língua... O escritor torce a linguagem, a faz vibrar, a estreita, a fende, para arrancar o percepto às percepções, o afeto às afecções, a sensação à opinião. (Deleuze \& Guattari, 1995, p. 167)

Latour (2012) retoma e atualiza os argumentos de Souriau e de Deleuze e Guattari, num texto particularmente relevante para nosso argumento, quando fala dos seres de ficção: "Há sem dúvida alguma uma exterioridade nestes seres que se impõem a nós após serem impostos àqueles que os instauraram e que têm frente a eles o papel antes de mandantes do que de "criadores'” (p. 248). Não gostaríamos simplesmente de Bach. Aquele que diz "eu gosto de Bach" torna-se um sujeito capaz de gostar desta música. Latour (2012) brinca com nossa prática de baixar programas na internet: é como se a obra nos permitisse baixar a permissão de nos emocionarmos, tornando-nos "pouco a pouco 'amigos das obras interpretáveis"” (p. 248). Se o sujeito é tomado pela obra, não seria por sua subjetividade, 
mas porque a obra exigiria que ele fizesse parte de seu projeto de instauração... "Aquele que não se sente tomado e engendrado pelas exigências da obra jamais será habitado por ela" (Latour, 2012, p. 249): ele precisa se tornar sensível às obras que povoam o mundo.

Dizer que os seres de ficção povoam o mundo é dizer que eles vêm a nós e que eles se impõem, mas com isto de particular que eles têm necessidade, como Souriau havia tão justamente notado de nossa solicitude. Nós constituímos, diz ele, o "polígono de sustentação”! Seu estatuto próprio é que: "o composto deve se manter sozinho" como dizem Deleuze e Guattari. Mas se nós não os retomamos, se nós não os cuidamos, se nós não os apreciamos, eles correm o risco de desaparecer. Eles têm portanto isto de particular que sua objetividade depende da sua retomada pelas subjetividades que, elas mesmas, não existiriam sem que eles não as tivessem nos dado... devemos continuá-los sem entretanto inventá-los.... Nós nos encontramos em sua trajetória; nós somos uma parte do seu trajeto, mas sua criação contínua se encontra distribuída ao longo do caminho de vida de tais seres, ao ponto que nunca se sabe verdadeiramente se é o artista ou o auditório que faz a obra. Dito de outra forma, eles também fazem rede. (Latour, 2012, p. 250)

E aí está o mais intrigante, conclui Latour (2012): tudo isto "com certeza não se deve ao autor em carne e osso” (p. 254). Portanto, a noção de estilo tal e qual disposta nesse resgate de autores bem como nas digressões que aqui nos permitimos, nos levam a refletir acerca do impacto desse pensamento para discutirmos uma noção de eu não moderna, ou seja, não segregada do mundo e das afetações que atravessam os modos de existência. Reuniremos a seguir os principais pontos a serem destacados para essa discussão.

\section{Síntese e discussão}

Retomando o que expusemos até esse ponto, podemos elaborar uma sequência de pontos, cujos nortes estão grifados (com aspas), que configurariam a noção de estilo de um ponto de vista não moderno.

1- O estilo exige uma dedicação que redunda numa "especialidade".

2- O estilo envolve a "atenção" do criador à obra.

3- Criador e obra são constituídos em redes de conexões".

4- Esta especialidade é praticada num "modo de existência" caracterizado por um conjunto de "condições de felicidade" e por uma "trajetória" que tem um "sentido" determinado indicado por uma "preposição".

5- Ao produzir a obra o artista faz com que ela "fique em pé".

6- Este fazer implica um método, uma sintaxe, um ritmo, "uma interpretação"6 original do autor.

7- A obra "solicita" o intérprete.

Vejamos, pois, como essa sequência opera em um exemplo a partir da obra de Heitor Villa-Lobos. 
1- Villa-Lobos não é, com certeza, um autor de fim de semana. Foi um músico brasileiro que se sobressaiu nas mais diferentes formas de escrita musical erudita e popular. Sua obra não se distrai com irrelevâncias e atinge seu fim de produzir música contemporânea brasileira.

2- Há um cuidado, uma atenção em suas composições em conciliar o erudito e o popular. Muitos títulos dos seus movimentos integram estes dois modos de expressão: p. ex. "Valsa-Choro" (da "Suite Popular Brasileira"), "o Trenzinho do Caipira”, (o movimento final da $2^{\text {a }}$ Bachiana Brasileira).

3- Não existe um Villa-Lobos tout court. Ele e suas composições são o resultado de uma rede de conexões que envolve todo um capítulo da história da música brasileira.

4- Um pesquisador pode traçar a trajetória que ele seguiu assumindo o modo de existência de "compositor", a forma como ele se submetia ou não às "condições de felicidade" exigidas para um músico e que justifiquem, deem sentido em qualificá-lo na preposição "músico brasileiro do século XX".

5- Ao ouvirmos as obras de Villa, não estamos tão interessados na dificuldade que ele teve para se separar de sua primeira mulher e viver com Mindinha, sua grande paixão: usufruímos simplesmente das obras que "ele colocou em pé".

6- Seu estilo consiste precisamente na maneira com que "torceu, fez vibrar, estreitou, fendiu” a música produzindo os blocos de sensação que conhecemos como as Bachianas Brasileiras ou Prelúdios para Violão.

7- As partituras de Villa entretanto não existiriam se não fossem lidas, tocadas, performadas. Elas solicitam uma interpretação para existir. Por exemplo, num belo disco de música instrumental, o tecladista Egberto Gismonti oferece uma versão insólita do seu "Trenzinho Caipira" com sintetizadores eletrônicos (que provavelmente muito teria agradado a Villa-Lobos). Do estilo de Villa-Lobos chegamos ao estilo de Gismonti.

Interessa-nos especialmente este exemplo da interpretação do "Trenzinho Caipira" de Villa-Lobos por Egberto Gismonti. A obra de Villa-Lobos solicitou o seu fazer, e nesta solicitação, Gismonti mobilizou um saber fazer que caracteriza tanto o velho Villa quanto ele e sua música instrumental.

É este acolhimento da solicitação que dispara o «saber fazer» que deixa marcas e compõe trajetórias que nos interessam, como psicólogos. É através deste exemplo que podemos propor uma generalização do estilo e sair da sofisticada esfera da arte maior trazendo este argumento para nosso cotidiano.

Podemos agora compreender o erro moderno que cometíamos ao perguntarmos se era mãe italiana que cozinhava de forma deliciosa ou a sua macarronada que era deliciosa. Diríamos, após nossa argumentação, que ela o fazia (exercendo seu saber fazer) "enquanto cozinheira" (seguindo o sentido desta preposição) realizando uma receita culinária "que não existiria” sem sua interpretação. Uma sucessão de exemplos pode ser proposta.

Os irmãos Taviani têm uma marca, uma trajetória, uma trilha, um sulco que deixa marcas, como cineastas (não como irmãos): do filme Pai Patrão (1977) ao Maravilhoso Boccaccio (2015) passando pelo Cesar deve Morrer (2012). Eles têm um estilo. O mesmo não valeria para Woody Allen, Quentin Tarantino, que têm um modo de dirigir mediante os filmes que realizam? 
Um indivíduo não pode ser um ótimo motorista de ônibus, preencher as "condições de felicidade" (respeitar o código de trânsito) de sua profissão de forma adequada, ser um artista "como" motorista?

Nestes exemplos, os atores não são especialistas em seus ofícios, não têm atenção às suas obras, não são resultados de redes de conexões, não seguem uma trilha, não respondem à solicitação de dispositivos que os fazem agir em diferentes modos de existência? Em nossa perspectiva, a resposta a todas essas perguntas é: sim.

Seguindo argumentação afim a esta que ora propomos, Law e Mol (1995) contam a história de Pasteur. "Assim, o que, ou quem era ele" perguntam eles? "Bem, isto é complicado", respondem os autores:

Há muitas respostas. Ele era um corpo físico, um organismo, um cidadão francês, um político cientista, um cientista de laboratório, um membro de família, um político fracassado. Depende de onde e como se olha. Este então é o ponto: Pasteur "o cientista de sucesso" é uma rede organizada, um efeito relacional. E também, sob outras circunstâncias, um ponto na rede. (Law \& Mol, 1995, p. 5)

A partir de nossas argumentações, perguntamos: qual seria o estilo de Pasteur? Diríamos que não haveria um Pasteur, um estilo, mas uma diversidade de Pasteurs, uma multiplicidade de estilos "como" corpo físico, "como" um organismo, "como" um cidadão francês, "como" um político cientista, "como" um cientista de laboratório, "como" um membro de família, "como" um político fracassado, uma sucessão de preposições associadas ao cumprimento (ou não, como no caso do político) de uma série de condições de felicidade

Assim, retomando a questão que inaugurou essa escrita, dizemos que a raiz do problema da concepção do eu é sua totalidade, nunca há um "eu” na prática: o "eu” sempre desempenha um modo ou outro, seguindo uma preposição ou outra (como Law e Mol argumentam no que tange a Pasteur). Nunca há sujeitos conhecedores ou objetos conhecidos, há redes de actantes em diferentes modos de existência, sejam tais redes o motorista, o garçom, o professor, o músico, o amante, o poeta, enfim todos aqueles que "fazem" alguma coisa, bem ou mal, respeitando ou não as condições de felicidade advindas da prática. Nada impede, entretanto, que um indivíduo possa estar em mais do que um modo, embora nada garanta que sua excelência num modo seja a garantia de excelência em outro modo. Isto é, uma coisa é considerar Chico Buarque "enquanto" compositor de canções, outra "enquanto" escritor. $\mathrm{O}$ eu seria esta articulação heterogênea de modos de existência num indivíduo, um monumento, uma arquitetura suscetível de modificações, como dizem Stengers e Latour (2009) numa leitura de Souriau:

O que dizer dos seres psíquicos? O que dizer de Monsieur Durand idêntico a si mesmo através de suas diferentes aparições fenomenais? Não do "Eu fenomênico" durandeiro cativado pela paisagem, não também do M. Durand radiante de felicidade por conta de um novo amor, suscitando a emoção de um amor perdido ou de um amor traído. Nós falamos aqui da "durandidade" que faz comunicar as diferentes aparições, que traduz a "monumentalidade" própria a M. Durand e faz de sua organização e de sua forma "a lei de uma permanência, de uma identidade". Esta durandidade é o que Souriau denomina uma alma, ou um "psiquismo.” (p. 43) 
Vejamos o próprio Souriau (2009) falando:

Tudo o que afirmamos dos psiquismos, neles constatando este mesmo modo de existir é que eles têm uma espécie de monumentalidade que faz da sua organização e sua forma a lei de uma permanência, de uma identidade. Longe de comprometer a vida concebendo-a desta forma, seria faltar com ela se não a concebêssemos como arquitetônica, como sistema harmônico suscetível de modificações, de acréscimos, de subversões e mesmo lesões... numa palavra, um ser. (pp. 127-128)

Se retomarmos a própria conceituação da palavra "estilo", deparamo-nos com um dos seus significados que é "maneira de fazer”, ratificando o caráter ativo dessa noção. Portanto, ao considerá-la para pensarmos um sujeito não moderno, deslocamos a ideia de sujeito, de psiquismo, de um espaço interiorizado, fixado ou estático como um traço, para os seus múltiplos "fazeres" articulados em redes, no sentido dado no início dessa escrita. Os fazeres aqui não devem ser reduzidos ao desempenho de papéis, visto que não estão meramente vinculados à socialização ou normatizações. Há uma ênfase na rede, na articulação heterogênea de modos de existência que nos permite pensar nesse sujeito em ação, que deixa o aprisionamento do ensimesmamento para atuar no mundo, nas redes locais, estabelecendo conexões parciais que podem criar outras possibilidades. Ao nos determos nas digressões e narrativas dos diversos exemplos aqui expostos, buscamos sustentar o quanto Villa Lobos, os irmãos Taviani, o bom motorista, a boa cozinheira, Chico Buarque, etc, performam seus modos de existir enquanto tal a partir dessa rede que os afeta e os constitui, e não a partir de uma identidade fechada, caracterizada por um eu absoluto. Nesse sentido, a preposição fará toda a diferença. Porque, como dito, a preposição é o que engancha uma certa relação, ela oferece o tipo de relação necessária para captar a experiência do mundo. O cerne é, pois, a relação.

Portanto, se considerarmos essa perspectiva nas práticas psis, deixamos de separar o sujeito do mundo e ele passa a se constituir como um processo revelado em suas múltiplas possibilidades de conexões. As conexões têm um caráter de impermanência. Nesta mesma diretriz de pensamento, Stenner (2012) propõe a noção de "padrão" (pattern), não no sentido normativo que o termo tradicionalmente possa sugerir, mas ele nos oferece justamente outra possibilidade de pensar o termo que, segundo ele, consiste numa alternância entre reunião e dispersão de multiplicidades (p. 137). O autor nos aponta, então, que a noção de padrão como dispositivo que se movimenta entre reunião e dispersão de elementos pode nos ajudar a evitar a clássica bifurcação sujeito/objeto e, consequentemente, redimensionar a fronteira entre subjetividade e objetividade.

Certamente essa reflexão merece maior aprofundamento, mas a trazemos aqui, na finalização dessa discussão, para reafirmarmos que nossas práticas nas ciências sociais carecem de outros olhares que nos afastem da certeza de um "indivíduo individualizado", caracterizado por um eu puro, interiorizado, constituído sem interferências e arranjos realizados no seu processo de estar no mundo.

Embora pensar essa questão no campo das artes não seja objeto desse artigo, tangenciamos essa área através de alguns dos nossos exemplos na medida em que a noção de estilo como maneira de fazer, como marca de um autor, parece encontrar ecos nesse setor, como nos apresentam os autores que nos acompanharam nessa reflexão. Tanto nas artes quanto na psicologia, nosso cuidado aqui é não reduzir a questão à ideia de personalidade, 
por exemplo, visto que essa tradição da psicologia não contempla nosso propósito. Portanto, tal como proposto por Souriau (2009), escapamos da monumentalidade e aproximamo-nos do estilo como um processo de criação, de construção que se dá nessa fronteira, nessa relação, nessa rede de humanos e não humanos. Assim, não é uma posse do sujeito, mas um fazerCOM (Moraes, 2010) uma proposição híbrida e fluída , uma composição múltipla e aberta que desafia o eu como instância fechada em si.

\section{Considerações finais}

Encontramos na noção de estilo uma pista que nos aponta outros caminhos conceituais que podem trazer contribuições interessantes para nossas práticas. Se consideramos uma noção de eu mais do que interferida, constituída por uma rede de afetos e afetações, se retirarmos desse conceito as limitações que o segregam de uma vida em ação, se deslocarmos a ideia de um eu interiorizado e pensante para uma multiplicidade de fazeres com contornos flexíveis, temos a possibilidade de pensar uma psicologia mais viva e ativa. Tomando o campo da clínica e/ou das instituições como exemplo, podemos compreender esse "eu” não mais como detentor de sua saúde ou adoecimento, ou simplesmente determinado por categorias nosológicas. Menos ainda pensá-lo como determinado pela sociedade com suas transformações. Esse humano está em relação, e isso deve ser compreendido como um processo que incluí também os não humanos, tal e qual preconiza Latour (1994, 2008) em sua noção de rede. O estilo, portanto é um processo aberto, que nos "faz" enquanto actante na rede. Retomando o alerta de Rose (2001), buscamos aqui uma possibilidade que nos permita pensar uma psicologia em ação, para além dos laboratórios do século XIX, uma psicologia que opere com fronteiras mais permeáveis e não fique refém de um eu e da consequente ideia de identidade. O estilo tomado aqui como "maneira de fazer", e configurado a partir da noção de rede, nos leva a uma possibilidade mais arejada como os modos de existência que ressoam das ideias de Whitehead, de Souriau e Deleuze e das proposições de Latour (2012).

\section{Notas}

1 Para conhecer e mapear o campo dos estudos ator-rede, recomendamos Law (2008).

2 Somos um grupo de psicólogos que há tempos vem pesquisando e publicando sobre a psicologia pensada através de um referencial não moderno. Não vamos, por questões de espaço, nos alongar na explicitação das bases conceituais e metodológicas de nosso trabalho neste ensaio. Reportamos o leitor a alguns de nossos textos já publicados sobre o tema no Dossiê da Teoria ator-rede, revista Estudos e Pesquisa em Psicologia 15(4) de 2015, acesso em 20/07/2016, disponível em http://www.e-publicacoes.uerj.br/index.php/revispsi/ issue/view/963

3 Grupo de pesquisa CNPq composto por docentes, doutorandos, mestrandos e graduandos da Universidade do Estado do Rio de Janeiro (UERJ), Universidade Federal do Rio de Janeiro (UFRJ) e Universidade Federal Fluminense (UFF) que buscam pensar a psicologia através da TAR. 
4. Ao final do seu livro já se desenhava este movimento (Latour, 2008).

5 Preposição é a palavra que estabelece uma relação entre dois ou mais termos da oração. Essa relação é do tipo subordinativa, ou seja, entre os elementos ligados pela preposição não há sentido dissociado, separado, individualizado; ao contrário, o sentido da expressão é dependente da união de todos os elementos que a preposição vincula. Recuperado de http://www.soportugues.com.br/secoes/morf/morf80.php

6 Ao sustentar que o autor é um estrangeiro que gagueja em sua própria língua, entendemos que Deleuze (1968) se refere implicitamente à sua crítica à imagem do pensamento, contra o bom senso e o senso comum, desenvolvida no $3^{\circ}$ capítulo de seu livro Diferença e Repetição.

\section{Referências}

Arendt, R. (2008). Maneiras de pesquisar no cotidiano: contribuição da teoria do ator-rede. Psicologia e Sociedade, 20(n.spe.), 7-11.

De Negri, G. G. (Produtor), Taviani, P., \& Taviani, V. (Dir.). 1977. Padre padrone [Filme]. Itália: Rai 2 / Cinema S.r.l.

Deleuze, G. (1968). Différence e Répéttion. Paris: PUF.

Deleuze, G. \& Guattari, F. (1995). Qu'uest-ce que la philosophie? Paris: Minuit.

Deleuze, G. \& Parnet, C. (2008). Dialogues. Paris: Champs Essais.

Figueiredo, L. C. \& Santi, P. (2008). Psicologia, uma (nova) introdução: uma visão histórica da Psicologia. São Paulo: EDUC.

Latour, B. (1994). Jamais fomos modernos. São Paulo: Ed. 34.

Latour, B. (2007). A textbook case revisited: Knowledge as a mode of existence. Recuperado de http://www.bruno-latour.fr/sites/default/files/99-HANDBOOK-GB.pdf

Latour, B. (2008). Reensamblar lo social: uma introdución a la teoria del actor-red [Reassembling the social: An introduction to Actor-Network Theory] (G. Zadunaisky, Trad.). Buenos Aires: Manantial.

Latour, B. (2012). Enquête sur les modes d'existence. Paris: La Découverte.

Law, J. (2008). On sociology and STS. Sociological Review, 56(4), 623-649.

Law, J. \& Mol, A. (1995). Notes on Materiality and Sociality. The Sociological Review, 43(2), 74-94.

Musini, L. et al. (Produtores), Taviani, P., \& Taviani, V. (Diretores). 2015. Maraviglioso Boccaccio [Filme]. Itália; França: Stemal Entertainment / Cinemaundici.

Moraes, M. (2003). Alianças para uma psicologia em ação: sobre a noção de rede. Recuperado de www.necso.ufrj.br/Ato2003/MarciaMoraes.htm

Moraes, M. (2010) PesquisarCOM: política ontológica e deficiência visual. In M. Moraes \& V. Kastrup (Orgs.), Exercícios de ver e não ver: arte e pesquisa com pessoas com deficiência visual (pp. 26-51). Rio de Janeiro: Nau Editora.

Quadros, L. C. T. (2015). Uma trama tecida com muitos fios: o pesquisar como processo artesanal na Teoria ator-rede. Estudos e Pesquisas em Psicologia, 15(4), 1181-1200. Recuperado de http://www.e-publicacoes.uerj.br/index.php/revispsi/article/view/20253/14596

Rose, N. (2001). Como se deve fazer a história do eu? Educação \&̊ Realidade, 26(1), 33-57.

Souriau, E. (2009). Les différents Modes d'existence. Paris: PUF. 
Stengers, I. \& Latour, B. (2009). Le sphinx e l'œuvre [Présentation]. In E. Souriau, Les différents modes d'existence (pp. 1-75). Paris: PUF.

Tsallis, A. C., Ferreira, A. A. L., Moraes, M., \& Arendt, R. (2006) O que nós, psicólogos, podemos aprender com a teoria ator-rede? Interações, 12(22), 57-86.

Stenner, P. (2012). Pattern. In C. Lury \& N. Wakford (Eds.), Inventive methods: The happening of the social (pp. 136-146). London; New York: Routledge.

Volpi, G. (Produtor.), Taviani, P., \& Taviani, V. (Diretores.). 2012. Cesare deve morire [Filme]. Itália: Kaos Cinematografica.

Whitehead, A. N. (1959). The aims of education and other essays. New York: Basic Books.

\section{RONALD ARENDT}

http://orcid.org/0000-0002-74.17-2943

Doutor em Instituto Superior de Pesquisas Psicossociais Isop pela Fundação Getúlio Vargas, RJ (1987). Vice-líder do grupo de pesquisa Cnpq - Entre_ redes. Professor titular, Instituto de Psicologia. Docente permanente no Programa de Pós-graduação em Psicologia Social da Universidade do Estado do Rio de Janeiro.

Endereço institucional: Rua São Francisco Xavier, 524, sala 10019, bloco "f", Maracanã - Rio de Janeiro?RJ, Brasil.

E-mail: arendt.ronald@gmail.com

\section{LAURA CRISTINA DE TOLEDO QUADROS \\ http://orcid.org/0000-0002-3546-4935}

Doutora em Psicologia pelo Programa de Pós-graduação em Psicologia Social/ Universidade do Estado do Rio de Janeiro (UERJ). Participa do grupo de pesquisa CNPq "Entre redes ". É coordenadora do projeto de extensão(UERJ) COMtextos: arte e livre expressão na abordagem gestáltica e vice-coordenadora do projeto de extensão (UERJ) "Laboratório Gestáltico: configurações e práticas contemporâneas". Universidade do Estado do Rio de Janeiro. Professora adjunta no Instituto de Psicologia. Docente permanente no Programa de Pós-graduação em Psicologia Social.

E-mail: lauractq@gmail.com

\section{MÁRCIA OLIVEIRA MORAES}

http://orcid.org/0000-0002-8581-6126

Doutora em Psicologia Clínica pela PUC/SP. Bolsista Produtividade Cnpq. Cientista do Nosso Estado / FAPERJ. Professora titular no Departamento de Psicologia./ Instituto de Psicologia da Universidade Federal Fluminense. Docente permanente do Programa de Pós-graduação em Psicologia da Universidade Federal Fluminense. Líder do grupo de pesquisa $\mathrm{CNPq}$ Entre-redes. Bolsista Faperj / Cientista do Nosso Estado. Bolsista Cnpq.

E-mail: mazamoraes@gmail.com 


\begin{tabular}{ll} 
Histórico & Submissão: 11/12/2017 \\
& Revisão: 25/09/2018 \\
& Aceite: $28 / 10 / 2018$ \\
& Concepção: RA;LCTQ; MOM \\
& Coleta de dados: não se aplica \\
& Análise de dados: não se aplica \\
& Elaboração do manuscrito: RA;LCTQ; MOM \\
& Crítica de conteúdo intelectual importante: RA;LCTQ; MOM \\
Contribuição dos autores & Aprovação final do manuscrito: RA;LCTQ; MOM \\
& Marcia Oliveira Moraes é bolsista de produtividade em Pesquisa / \\
& CNpq e é também Cientista do Nosso Estado / Faperj. \\
\hline Financiamento & Não se aplica
\end{tabular}

